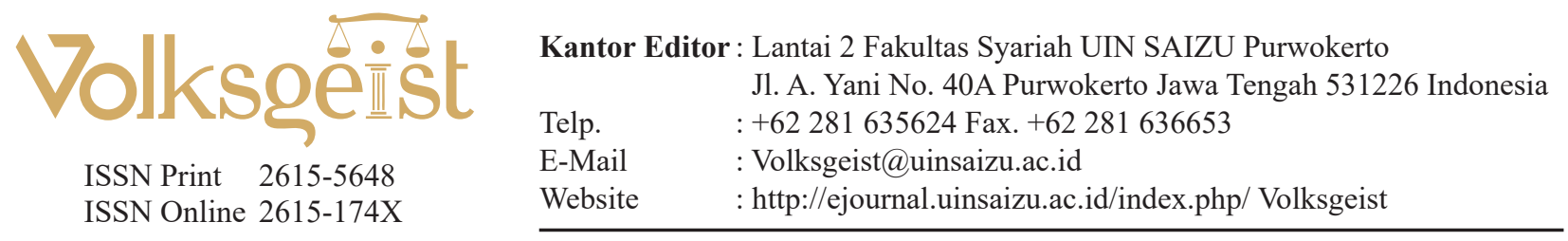

\title{
Dinamika Hukum Keluarga Islam dan Isu Gender di Iran: Antara Pemikiran Elit Sekuler dan Ulama Islam
}

\author{
Fathonah K. Daud, ${ }^{1}$ Aden Rosadi \\ ${ }^{1}$ Pascasarjana UIN Sunan Gunung Djati Bandung \\ Email: fathkasuwi@gmail.com
}

\begin{abstract}
Abstrak
Tulisan ini bertujuan mengkaji dinamika hukum keluarga di Republik Islam Iran. Dimana adanya pergolakan dan pertarungan dari kalangan elit sekuler dengan Ulama di Iran dari tahun 1927 hingga hari ini. Adapun metode penulisan artikel ini menggunakan library research dengan menggali informasi yang berkaitan dengan tema kajian. Hasil penelitian ini menunjukkan bahwa Republik Islam Iran yang dominan menganut Syi'ah Imamiyyah (Ja'fari). Tetapi juga mengakomodir mazhab Hanafi (Sunni) di bidang hukum perkawinannya. Hukum keluarga Iran telah melalui banyak perubahan. Sejak1928 masalah perceraian dan perkawinan yang awal telah diatur dalam Qanun Madani Iran mulai berlaku tahun 1930, Marriage Law kemudian ditetapkan tahun 1931. Setelah tiga dekade berlalu, pada tahun 1967 terjadi reformasi, Marriage Law digantikan Family Protection act, hingga pada tahun 1975 diganti dengan Protection of Family. Hukum-hukum tersebut merupakan kombinasi antara hukum Islam dan Yurisprudensi civil Prancis, tetapi lebih terkesan sekuler. Namun, hukum tersebut sejak Revolusi Iran 1979 telah dihapus dan semua hukum di Iran dikembalikan kepada hukum syariah. Dampaknya hukum menjadi represif terhadap perempuan, kecuali di bidang waris yang memberikan kesetaraan gender. Sementara telah banyak perempuan yang berpendidikan tinggi di Iran, sehingga sejak 2006 perempuan banyak yang mengajukan perceraian. Di sisi lain, secara de facto, praktik nikah mut'ah telah mulai ditinggalkan dan poligami ditentang oleh masyarakatnya.
\end{abstract}

Kata Kunci: Hukum Keluarga, Hukum Perkawinan, Perempuan di Iran

\section{Abstract}

This article examines the dynamics of family law in the Islamic Republic of Iran where there are upheavals and struggles between the secular elites and ulama from 1927 to the present day. This study applied a library research by digging up information related to the theme of the study. The results of this study indicate that the Islamic Republic of Iran is dominantly Shia Imamiyyah (Ja'fari) but it also accommodates the Hanafi (Sunni) School in the field of marriage law. Iranian family law has gone through many changes. Since 1928 the issue of divorce and marriage which was originally regulated in Iran's Qanun Madani came into force in 1930, the Marriage Law was then enacted in 1931. After three decades, in 1967 there was a reformation, the Marriage Law was replaced by the Family Protection act, then it was replaced with the Protection of Family in 1975. These laws are a combination of Islamic Law and French civil Jurisprudence, though they seem more secular. However, since the Iranian Revolution in 1979, these laws have been abolished and 
all laws in Iran have been returned to sharia law. As a result, the laws become repressive against women, except in the field of inheritance which provides gender equality. While there have been many highly educated women in Iran, since 2006 many women have filed for divorce. On the other hand, the practice of mut'ah marriage has begun to be abandoned and polygamy is opposed by the community.

Keywords: Family law; marriage Law; Women in Iran.

\section{Sejarah Artikel}

Dikirim: 30 Agustus 2021

Direview: 09 November 2021

Diterima: 23 November 2021

Diterbitkan: 30 November 2021

\section{PENDAHULUAN}

Negara Republik Islam Iran (Islamic Republic of Iran) merupakan bagian Negara Muslim di Timur Tengah yang undangundangnya telah mengalami banyak perubahan. Sejak Iran menjadi wilayah Dinasti Umayyah, seketika itu mengikuti hukum Islam, lalu pernah berubah menjadi modern, kalau tidak disebut sekuler. sejak pasca Revolusi Iran kembali kepada hukum syariat .

Secara historis, perubahan hukum Islam di Iran cukup dinamis. Tercatat sejak awal 1906, konstitusi pertama diundangkan. Lalu ditetapkan secara berturut-turut hukum perdagangan, jinayah, hak sipil dan hukum keluarga. Namun, pasca Revolusi Iran tahun 1979 terdapat perubahan lagi hingga pada era rezim hari ini.

Islamic Family Law Iran awalnya dikodifikasikan sebagai bagian dari Qanun Madani Iran mulai tahun 1928 sampai 1935. Qanun Madani ini dalam bentuk Iranian Civil Code (Hukum Perdata Iran), yang merupakan hasil kombinasi antara hukum Islam dan Yurisprudensi civil Prancis. ${ }^{1}$ Keadaan ini

1 Tahir Mahmood, Family Law Reform in The Muslim World (Bombay: (Bombay: N.M. Tripathi PVT. Ltd., 1972), 15. terjadi setelah Turki (1917), Sudan (1918) dan Mesir (1920) melakukan reformasi hukum keluarganya. $^{2}$ Persoalan perubahan hukum keluarga, termasuk yang berkaitan dengan isu gender, di Iran ini bahkan dapat dipandang sangat liberal sekaligus ekstrim. Namun setelah 5 dekade, awal tahun 1980-an, pasca Revolusi Iran dan dalam Wilayat al-Faqih, ${ }^{3}$ otoritas Iran yang baru melakukan perubahan dan lembali ke hukum syariah.

Kini, hukum Republik Iran modern bersumber dari syariah, adat, undang-undang dasar, dan prinsip-prinsip revolusi Islam Iran. Adapun Qanun Madani Iran mengikuti fiqh Ja'fari (Imamiyah), sehingga nikah mut'ah yang menjadi salah satu ajaran khas madzhab Syiah (ahlû al-Tasyayyu') termaktub dalam Qanun Madani tersebut. Maka, semua perun-dangan perdata di Iran modern semuanya harus sejalan dengan hukum Islam. Demikian juga sistem peradilan di tingkat pusat, Mahkamah Agung (MA) dan Jaksa Agung yang dipilih harus dari seorang yang mampu berijtihad dalam hukum Islam.

Republik Iran nampaknya lebih ketat

2 Welchman, Lynn. women and Moslem Famly Laws in Arab States: A Comparative Overviews of Textual Developmen and Advocacy. (Amsterdam: ISIM/ Amsterdam University Press, 2007), 13.

3 Wilayat al-Faqih difahami secara sederhana adalah sebuah sistem pemerintahan yang kepemimpinannya di bawah kekuasaan seorang Faqih (Imam) adil dan berkompeten dalam urusan agama dan dunia atas seluruh kaum Muslimin di Negeri Islam. tetapi baru dipopulerkan oleh Ayatullah Khumaini pada tahun 1979.54 
dalam menempatkan pemangku sebuah jabatan dalam hukum Islam yang strategis. Namun, bukan berarti perundang-undangan di Iran sudah final. Meskipun telah melakukan beberapa kali amandemen, perundang-undangan di Iran kini masih dipandang kurang properempuan. Diawali Kitab Qanun Madani mulai 1928 hingga 1935 yang diamandemen pada tahun 1982, Family Protection Law (hukum perlindungan keluarga) yang dibatalkan setelah revolusi Iran tahun 1979, Special Civil Courts Act 1979 dan UU 1992 yang mengamandemen aturan tentang perceraian. ${ }^{4}$

Tulisan ini meneliti perkembangan pembaharuan dan perubahan-perubahan hukum keluarga di Negara Islam Iran. Dari awal tahun 1928 hingga era modern ini, Pembahasan ini akan mencakup sejarah reformasi, ulasanulasan utama hukum keluarga. Termasuk bagaimana dampak dari modernisasi Iran praRevolusi bagi perlindungan hak-hak perempuan dan perkembangan fenomena praktik nikah mut'ah di Negara Syiah ini.

Data penelitian ini didapatkan dari studi literature (library research). Metode ini memanfaatkan sumber-sumber kepustakaan yang berkaitan Islamic Family Law di Negara Iran dan memperdalan kajian teoritis atau mempertajam metodologis dengan tanpa peneliti terjun ke lapangan. ${ }^{5}$

Adapun kajian tulisan terdahulu terdapat karya Ziba Mir Hosseini, Marriage on Trial: a Study of Islamic Family Law, Iran and Marocco Compared, yang merupakan revisi dari disertasinya di Cambridge University. Penelitian ini tentang kajian antropologi komparatif hukum keluarga di Iran dan

4 Mallat, Chibli. 1993. The Renewal of Islamic Law: Muhammad Baqer as-Sadr, Najafand the Shi'i International. Cambridge: Cambridge University Press. 15

5 Zed, Mestika, Metode Penelitian Kepustakaan (Jakarta: Yayasan Pustaka Obor Indonesia, 2014), 1-3
Maroko. Terutama tentang problematika perempuan dalam menghadapi perceraian di pengadilan agama di Iran dan Maroko, antara tahun 1985-1988. Kekuatan kajian tersebut terletak pada sketsanya yang dramatis dan mengharukan perempuan yang bercerai dan berjuang untuk mengatasi sistem hukum yang represif terhadap perempuan. ${ }^{6}$ Tulisan kedua, Family Law and Family Planning Policy in Pre and Post-Revolutionary Iran, karya Homa Hoodfar. Penelitian ini tentang hukum kelu-arga dan kebijakan keluarga berencana (KB) pra dan pasca Revolusi Iran. Tulisan ini memandang Iran sebagai Negara non-Barat tetapi paling sukses dalam program KB. Ini sungguh menarik, karena ideologi politik rezim Islam pernah menolak KB. ${ }^{7}$ Demikian juga Tahir Mahmood yang bertema Family Law Reform in The Muslim World. Dalam buku tersebut antaranya diulas 'reformasi Hu-kum Keluarga di Iran' yang berkembang sekitar 7 tahun sebelum Revolusi Iran. Tulisan tersebut memaparkan Hukum Keluarga Iran pada era awal hingga 1972 saja. $^{8}$ Selain itu, sebuah artikel Kontribusi Iran terhadap Sejarah Pembaharuan Hukum Keluarga Islam (Potret Sistem Kewarisan dan Wasiat Wajibah di Iran karya Muhammad Fauzinuddin. Kajian ini terfokus pada potret sistem kewarisan di Iran yang sudah berperspektif gender. ${ }^{9}$ Tentu saja artikel ini berbeda dengan kajian-kajian

6 Mir Hossein, Ziba, Marriage on Trial: a Study of Islamic Family Law, Iran and Marocco Compared, (London: St. Martin's Press, 1993)..

7 Hoodfar, Homa, Family Law and Family Planning Policy in Pre- and Post-Revolutionary Iran, (London: Routledge, 2008) https//doi. org/10.4324/9780203894057.

8 Tahir Mahmood, Family Law Reform in The Muslim World,....

9 Muhammad Fauzinuddin, Kontribusi Iran terhadap Sejarah Pembaharuan Hukum Keluarga Islam (Potret Sistem Kewarisan dan Wasiat Wajibah di Iran), Ulul Albab, vol. 18, no. 2, 2017. 210 https://doi. org/10.18860/ua.v18i2.4492 
tersebut. Bahkan kajin-kajian tersebut merupakan literature penting dalam tulisan ini.

\section{PEMBAHASAN}

\section{Sekilas Tentang Republik Islam Iran}

Iran merupakan Negara di kawasan regional Asia Barat. Sejarah Iran telah melalui perjalanan yang sangat panjang, dan telah diperintah oleh beberapa dinasti selama kurang lebih 2.500 tahun. Negara Iran dahulunya merupakan bagian dari peradaban Perthia (2700 $\mathrm{SM}$ ), atau Sassanid yang merupakan musuh bebuyutan Romawi. ${ }^{10}$

Islam memasuki wilayah Persia tahun 633 dan takluk sepenuhnya tahun $644 .{ }^{11}$ Wilayah ini kemudian mampu membantu Dinasti Abbasiyyah (750-1258) untuk mela-wan tentara Umayyah, yang menindas warga non Arab Muslim. Bahkan sebagiannya menentang Arabisasi dengan cara mendirikan dinasti Islam sendiri dan menggunakan bahasa Parsia sebagai bahasa resmi hingga hari ini.

Pada era Dinasti Safawiyyah (15011722), ${ }^{12}$ Parsia berubah menjadi Islam Syi'ah. Kemudian dikuasai Dinasti Afshariyyah (1736), Zand (1751), dan Qazar (1796-1925). Setelah itu Dinasti Pahlevi 15 Desember 1925-1979. Namun, Republik Islam Iran baru berdiri pada 1 April 1979 dalam sebuah revolusi besar, yang berdampak luas ke dunia internasional. ${ }^{13}$

Warga Iran sendiri menyebut bang-sanya 'Negeri Arya' (Masyarakat termasyhur). Sementara orang luar menyebut Parthia, yang

\footnotetext{
10 Akhavi, , -Iranll, The Oxford Encyclopedia of The Modern Islamic World, ed. John L. Esposito (Oxford: Oxford University Press, 1995), jilid-II, 225

11 Homaidi Hamid, -Hukum Keluarga Iranl, Hukum Keluarga di Dunia Islam Modern, ed. M. Atho“ Muzdhar, dkk. (Ciputat: Ciputat Press, 2003), 54."

${ }^{12}$ Don Peretz, The Middle East Today (New York: Preegar, 1986), 504

13 Elvi Soeradji, Dinamika Hukum Islam di Iran, Jurnal HIMMAH, Vo. 8 (22), Mei 2007, 38 http://digilib. iain-palangkaraya.ac.id/id/eprint/2392
}

merujuk pada Pars, sebuah wilayah selatan Iran, hingga tahun $1935,{ }^{14}$ kemudian pemerintah Teheran secara resmi mengumumkan penggunaan nama Iran.

Wilayah Iran seluas $1.648 .000 \mathrm{~km}^{2}$, terdiri dari 24 propinsi dan beribu kota Teheran. Wilayahnya di sebelah utara berba-tasan dengan laut Republik Caspian, Azer-baizan, Turkmenistan dan Armenia; di sebelah timur Pakistan dan Afganistan; di sebelah selatan Teluk Persia dan Oman; dan di sebelah barat Turki dan Irak. Meskipun mayoritas warga Iran adalah orang Persia, Iran memiliki populasi yang bervariasi etnisnya, dengan multi budaya, bahasa dan pakaiannya sendiri.

Pada Perang Dunia II, Uni Sovyet dan Inggris memerangi Iran, 25 Agustus 1941. Pada akhir perang Dunia II, Iran masuk menjadi anggota Negara Blok Barat tahun 1950. Atas dasar tersebut, Amerika memberikan dukungan ekonomi dan politik kepada Iran, sebagai keanggotaan mereka di blok Barat. Setelah itu, tahun 1951, National Front bentukan Mossadegh menjadi pemerintahan Iran pertama yang terpilih secara demokratis. Namun, 1953 ia digantikan dalam kudeta militer yang dimotori CIA dan Intelegen Inggris. Tahun 1953 Shah Reza Pahlevi kembali memimpin hingga revolusi 1979.

Iran modern merupakan salah satu Negara yang mendeklarasikan diri sebagai Negara Islam, dengan populasi terbanyak di Asia Tengah, sekitar 78.511.100 jiwa (2015). ${ }^{15}$ Rata-rata penduduknya muslim 95,5\%, sisanya penganut Zoroaster (Majusi), Yahudi, Kristen dan Bahai. ${ }^{16}$ Mayoritas umat Islam dengan 89\%

14 Kedutaan Republik Indonesia Iran, Selayang Pandang Republik Islam Iran, (Tehran: KBRI, 2008), 3.

15 Iran News, Payvand.com. Irans Population growth rate falls to 1,5 percent: UNFP, Diakses pada tanggal 27 Mei 2021.http://www.payvand.com/news/04/ aug/1017.html

16 Sachiko, Murata. 1974. Temporary Marriage in Islamic Law. Electronic publication based on MA dissertation completed in 1974 at the Faculty of 
penganut Syi'ah Ja'fari. Sisanya Islam Sunni mazhab Hanafi, sekitar $8 \%$ saja. ${ }^{17}$

\section{Kodifikasi Hukum Keluarga Islam Iran}

Ketika Uni Sovyet menyerang Iran, saat itu modernisasi terjadi di Turki dan Mesir, keadaan ini menyadarkan Iran untuk memikirkan kembali struktur politik negeri mereka. Beberapa tokoh telah memberikan sumbangan pemikiran modern di Iran, seperti Ali Syariati 'ideolog revolusi', ${ }^{18}$ Malkum Khan (1833-1908), seorang Armenia Muslim berpendidikan di Prancis, dan Abd al-Rahim Talibov (1834-1911), seorang pedagang yang pernah tinggal di Rusia. Termasuk Jamal alDin al-Afghani dan Mirsa Aga Khan Kermani telah menekankan doktrin anti-imperialis dan membangkitkan semangat nasionalisme untuk menentang campur tangan Barat.

Paling awal Iran mengadakan Revolusi Konstitusi pada 1905-1911. Kemudian Menteri Kehakiman Iran menunjuk komisi untuk mengkonsep draft Qanun Madani. Materi hukum-hukum yang umum diambil dari Napoleon Code, yang dipandang tidak berbenturan dengan syari'ah Islam. Sementara materi-materi berkaitan dengan hukum keluarga dan waris lebih mencerminkan unifikasi dan kodifikasi hukum syari'ah. Draft yang disusun oleh komisi tersebut ditetapkan sebagai Qonun Madani dalam tiga tahap, antara 1924-1928, ${ }^{19}$ dan disempurnakan pada 1935. Code ini terdiri dari 10 buku, yang terdiri dua bagian.

Theology at Tehran University (most of the Persian text has been published under the title izdiwaz-i muwaqqat: mut'a sigha. Tehran: Hamdani, 1358/1979) Download from www.Al-Islam.org/organizations/dilp, the Ahlul BaytDigital Islamic Library Project.

17 Abdullahi A. an-Na'im, Islamic Family Law in a Changing World: A Global Resource Book (London: Zed Book Ltd., 2003), 108

${ }^{18}$ Elvi Soeradji, Dinamika Hukum Islam di Iran,. , 39 http://digilib.iainpalangkaraya.ac.id/id/eprint/2392

19 Mahmood, Tahir, Family Law Reform in the Muslim World...,154
Bagian draft yang me-nyangkut perkawinan, perwalian, pemelihara-an anak, waris dan wasiat, menggambarkan sebuah kodifikasi hukum syariah dan meru-pakan hasil pemikiran dua faqih Iran, Muham-mad Fatimi dan Kazim Assar. Selanjutnya berdasarkan draft tersebut, Komisi Legislatif Iran mengaktifkan Qanun Madani.

Marriage Law seluruhnya diatur dalam bab VII, didasarkan pada hukum tradisional fiqh Syi'ah Imamiyah dan mazhab Sunni Hanafi. Hukum perkawinan dan perceraian, secara terpisah telah diterapkan tahun 1931. Sebagian materinya bersumber dari pertim-bangan sosial budaya dan administratif. ${ }^{20}$ Sedang Hukum waris termaktub dalam pasal 861-949. Hukum waris ini berlaku sampai sekarang. Sementara hukum perkawinan dan perceraian tidak terhindar dari reformasi hukum. ${ }^{21}$ Reformasi hukum pada era kepemimpinan Reza Shah dilakukan oleh Lembaga Legislatif Iran, dengan diundang-undangkan hukum perlindungan keluarga (Family Protection act) pada 24 Juni 1967. Family Protection act (FPA) ini telah dire-formasi hukumnya bersifat administratif dan substantif, yang terdiri 23 pasal. Adanya FPA ini diharapkan dapat mengatur secara tegas hukum perceraian dan poligini agar terhindar dari tindak kezhaliman. Pada era tersebut hakhak perempuan mulai mendapat perhatian dan perlindungan. FPA ini kemudian diamandemen tahun 1975. Pada tahun ini juga gedung Pengadilan Agama khusus dibangun. ${ }^{22}$

Pada tahun yang sama, Protection of Family ditetapkan, yang digunakan untuk mengganti FPA. Dalam Undang-undang yang baru ini, dimasukkan hukum perceraian dalam Undang-Undang sebelumnya, termasuk me-

20 Mahmood, Tahir,Family Law Reform in the Muslim World...,155

21 Mahmood, Tahir,Personal Law in Islamic Countries (New Delhi, 1987), 216

22 Abdullahi A. an-Na'im, Islamic Family Law in a Changing World: A Global Resource Book (London: Zed Book Ltd., 2003), 108 
masukan perubahan-perubahan yang signifikan. UU ini juga memberi batasan izin poligini oleh pengadilan. ${ }^{23}$

\section{Perjalanan Hukum Perkawinan di Iran}

Masalah pernikahan dan perceraian yang awal telah diatur dalam Iranian Civil Code dan mulai berlaku tahun 1930. Marriage Law kemudian ditetapkan tahun 1931. Setelah tiga dekade berlalu, pada tahun 1967 Marriage Law ini digantikan FTA, dan kemudian pada tahun 1975 diganti dengan Protection of Family.

Selain itu, yang perlu mendapat perhatian bahwa materinya dari hukum Islam, tetapi telah bersentuhan dengan undang-undang Eropa. Tentu saja memberikan nuansa baru terutama dalam isu gender. Bahkan terkesan lebih liberal. Sepanjang era Reza Syah Pahlevi (1941-1979), budaya Iran telah bertukar dan berubah layaknya cara hidup orang-orang Barat. ${ }^{24}$ Praktik-praktik lama tra-disional dihapuskan dan ditanamkan corak kehidupan yang baru diimpor dari luar. Misal-nya tahun 1930, Shah Iran melarang kaum perempuan memakai chador (pakaian perem-puan Iran yang menutup seluruh tubuhnya), apabila masih dipakai, polisi akan melepas-kannya secara paksa. ${ }^{25}$ Pendidikan pun mulai diterapkan sistem sekuler. Bersama itu didi-rikan Universitas Teheran pada 1935 dengan membuka fakultas pendidikan Eropa. Terma-suk mengirimkan pelajar ke luar negeri untuk menyerap pemikiran Barat.

Namun pasca revolusi 1979 telah terjadi reformasi di Iran, segala yang telah dicetuskan pada era Dinasti Pahlevi dihapuskan, karena dinilai telah melampaui ketentuan hukum Islam

23 Mahmood, Tahir,Personal Law in Islamic Countries,....., 217

24 Stewart, Devin J. 1998. Islamic Legal Orthodoxy: Twelver Shiite Responses to The Sunni Legal System. Salt Lake City, UT: University of Utah Press, 2-3

25 Esposito, Jhon, Ensiklopedi Oxford Dunia Islam Modern, Jil. 2, Penerj. Eva Y.N. dkk, (Bandung: Mizan, 2001), 69. yang mapan. Sejak kesuksesan Revolusi Iran ini, pemimpin yang baru mengumumkan bahwa syariat Islam telah menjadi sumber utama hukum di Negara Islam Iran. Hukum Keluarga yang dipergunakan dikembalikan pada mazhab Syi'ah Istna Asyari (mazhab mayoritas) dan mazhab Sunni Hanafi.

\section{Hukum keluarga Iran Pra dan Pasca- Revolusi Perspektif Fiqh}

Berikut ketentuan hukum keluarga Iran pra-Revolusi (1930-1979) hingga post Revolusi. Untuk memudahkan memahami gambaran dinamika hukum keluarga Iran, penulis paparkan studi komparatif bagaimana dari sisi fiqhnya, karena Hukum Keluarga Pasca Revolusi dikembalikan kepada hukum Islam.

1. Pencatatan Perkawinan

Hukum Keluarga yang berlaku mengharuskan setiap perkawinan agar dicatatkan pada lembaga yang berwenang. Pencatatan perkawinan ini berlaku bagi nikah daim maupun nikah mut'ah. Sebe-lum perkawinan, masing-masing calon mempelai harus mendapat sertifikat kese-hatan terlebih dahulu dari pihak medis. Bagi yang tidak mencatatkan pernikahan-nya dikenai hukuman kurungan maksimal enam bulan. ${ }^{26}$

Apabila ditinjau regulasi pencatatan nikah ini termasuk dalam pembaharuan yang sifatnya regulatory (administratif), karena pelanggarnya hanya mendapat sanksi fisik, sementara kedudukan perni-kahannya tetap sah. Ketentuan seperti ini dapat dinilai pro perempuan. Akibat dari pernikahan yang tidak dicatatkan sering-kali membawa dampak buruk dan merugi-kan pihak perempuan. Maka dengan dica-tatkan dapat dipandang sebagai salah satu cara pemerintah untuk menertibkan per-kawinan juga untuk meminimalisir terjadinya kezaliman. Terkait keharusan pencatatan nikah ini sebenarnya

26 Tim Ahlul Bait Indonesia, Buku Putih Mazhab Syiah,(Jakarta: Dewan PP ABI, 2012), 75-79 
tidak ada bahasannya dalam fiqh, baik dalam mazhab Ja'fari maupun mazhab Sunni. ${ }^{27}$

\section{Perkawinan di Bawah Umur}

Dalam pasal 1031 Qonun Madani Iran memberi ketentuan usia minimum dalam perkawinan, usia bagi lelaki 18 tahun dan bagi perempuan 13 tahun. Apabila seseorang mengawini seorang gadis yang masih di bawah batasan minimum usia pernikahan, dapat dihukum penjara enam bulan hingga dua tahun. Jika seorang gadis dinikahkan sebelum usia 13 tahun, maka yang menikahkan kena sanksi penjara selama 2-3 tahun. Di samping itu, bagi orang yang melanggar ketentuan ini dikenai denda 2-20 riyal. Keterangan hukuman ini tertuang dalam pasal 3 Hukum Keluarga (19311937). ${ }^{28}$

Perlu mendapat perhatian bahwa ancaman sanksi bagi wali yang menikah-kan anaknya yang masih usia dini meru-pakan modernisasi hukum keluarga di Iran yang bersifat regulatory. Sebagaimana difahami, bahwa Alqur'an dan hadits tiada pernyataan demikian. Sehingga persoalan ini masih menjadi perbincangan di mana pun, bahkan batasan kedewasaan dalam fiqh penuh kritikan dari banyak kalangan. Demikian yang terjadi di beberapa Negara Islam juga berbeda-beda. Sering kali faktor kedewasaan anak dilihat secara biologis. Konsep baligh seperti itu berbeda-beda di setiap Negara, tergantung pada keadaan perkembangan teknologi yang dapat mempengaruhi pertumbuhan biologis masyarakat.

Tetapi dalam pandangan fiqh mazhab Ja'fari, bahwa perempuan dipandang telah dewasa apabila sudah berumur 9 tahun dan bagi pria telah berumur 15 tahun. Demikian

\footnotetext{
${ }^{27}$ Hukum Perkawinan, 1931, pasal 1

28 Suma, Muhammad Amin, Hukum Keluarga
} Islam di Dunia Islam (Jakarta: Rajawali Grafindo, 2005), 54. bagi seorang wali diperbolehkan menikahkan anaknya kurang dari usia tersebut. ${ }^{29}$ Jadi ketentuan undang-undang pra-Revolusi justru ada peningkatan batasan usia menikah dari fiqh Imamiyah. Meskipun usia 13 tahun ini bagi seorang gadis, dalam hukum di Indonesia terkait perlindungan anak no. 232002 atau no. 35 2014, masih dipandang usia anak-anak, karena belum mencapai usia 18 tahun.

\section{Perjanjian Perkawinan}

Para calon pengantin yang akan menikah boleh membuat perjanjian. Perjanjian tersebut dapat dilaksanakan di bawah perlindungan pengadilan dan isi perjanjian diharuskan tidak bertentangan dengan tujuan perkawinan.

Hal ini berbeda dengan fiqh klasik, yang tidak ada pembahasan mengenai perjanjian pernikahan. Pembahasan fiqh justru terkait pada persyaratan pernikahan. Menurut Mazhab Imamiyah (Syi'ah), syarat yang dinilai gugur dalam akad tidak dianggap dapat membatalkan akad nikah atau mahar itu sendiri, kecuali jika diisyaratkan dalam bentuk khiyar, atau tidak berlakunya semua dampak akad yang bertentangan dengan wataknya sendiri. Jika seorang istri ketika akad penikahan mensyaratkan kepada suami agar ia tidak menikah lagi, tidak menceraikannya, atau hak talak berada pada isteri saja, tidak boleh mewarisi, atau persyaratan lain yang bertentangan dengan tujuan akad nikah, maka persyaratan-persyaratan tersebut akan batal sendiri, sedangkan akad nikahnya tetap sah. ${ }^{30}$

\section{Poligini}

Regulasi yang berlaku menyatakan, bahwa seorang laki-laki yang bermaksud hendak

\footnotetext{
29 Syarifuddin, Amir, Hukum Perkawinan Islam di Indonesia (Jakarta: Kencana, 2007), 66

30 Mughiyah,Muhammad Jawad, Fiqih Perbandingan Lima Mazhab, alih bahasaMasykur A.B. (Jakarta: Lentera, 1999), 319-320
} 
poligini wajib menginformasikan statusnya kepada calon isterinya. Perbin-cangan tentang aturan poligini termaktub dalam Family Protection act, 1967, pasal 11 (c). Hukum ini menjelaskan bahwa suami yang ingin berpoligini harus mendapat izin dari istrinya. Apabila aturan tersebut dilanggar, isteri pertama berhak menuntut perceraian ke pengadilan. Selain itu, suami juga harus mendapatkan izin resmi dari pengadilan. Namun sebelum itu, pengadilan akan memeriksa kondisi suami terlebih dahulu apakah seorang yang mampu memberi nafkah lebih dari seorang istri; dan mungkinkah mampu berbuat adil tehadap isteriisterinya. Pelanggaran terhadap regulasi ini akan mendapat sanksi penjara selama 6 bulan hingga 6 tahun.

Pasal 16 berbunyi: "Seorang suami dilarang poligini kecuali ada izin dari isteri yang pertama atau karena alasan-alasan: (1) isteri pertama tidak mampu berjimak dengan suami, (2) berpenyakit yang tidak dapat sembuh, (3) dipenjara minimal 5 tahun, (4) sering miras, judi, dan semacamnya, (5) meninggalkan keluarga, (6) hilang. ${ }^{31}$

Aturan perizinan bagi yang hendak poligini ini dapat dianggap sebagai reformasi regulatory, karena yang melanggar hanya diberi sanksi, sementara pernikahannya sendiri tetap dipandang sah. Di sisi lain dapat dipandang sebagai reformasi substantif, karena seorang suami yang berpoligini tanpa izin istri pertama dapat menjadi alasan bagi isteri pertama untuk menuntut perceraian ke pengadilan.

Keharusan adanya persetujuan istri juga merupakan terobosan baru untuk tidak semenamena dalam pernikahan. Selain itu keharusan izin istri tersebut juga merupakan bagian dari cara untuk menjamin kerelaan pasangan dalam menjalani kehidupan berumah tangga, termasuk

31 Toha Andiko, Pembaharuan Hukum Keluarga di Dunia Islam (Analisis terhadap Regulasi Poligami dan Keberanjakannya dari Fiqh), NUANSA: vol. 12, no. 2, 2019, 301http://dx.doi.org/10.29300/nuansa.v12i2.2807 menjamin dan adanya kesejah-teraan pasangan dalam berkeluarga.

Namun, ketentuan yang demikian itu tidak ditemukan dalam mazhab Ja'fari maupun mazhab Hanafi. Tetapi itu adalah hukum praRevolusi. Adapun UU poligini kini di Iran kembali sebagaimana di fiqh, tetapi justru ditentang oleh masyarakat. Meskipun syariat Islam membolehkan poligini ini, baik mazhab Syiah maupun Sunni. Agaknya masyarakat sudah mulai menyadari tentang pelaksanaan keluarga poligini yang rapuh.

\section{Nafkah Keluarga}

Suami bertanggungjawab dalam kewajiban nafkah pada keluarganya. Nafkah itu meliputi pangan, pakaian, papan, dan kebutuhan lainnya. Apabila seorang suami tidak menafkahi isteri dan anak-anaknya, sang isteri dapat melapor-kannya kepada pengadilan. Kemudian pengadilan meminta suami tersebut untuk memberikan nafkah wajib pada isterinya. Apabila suami tetap tidak memberi nafkah isterinya lebih dari enam bulan, maka istri berhak untuk mengajukan perceraian.

Ketentuan ini sesuai dengan fiqh bahwa apabila suami tidak mampu menafkahi keluarganya atas kelalaiannya, maka terhitung hutang. Untuk mengatasi hal ini ada dua pendapat: ${ }^{32}$

Pertama, bahwa sang isteri harus tetap bersabar dan taat pada suaminya. Tidak boleh minta cerai pada suaminya, jika suaminya sudah berusaha keras mencari nafkah.

Kedua, Islam mengajarkan mempergauli isteri dengan cara yang $m a^{c} r \hat{f} f$. Jika suami menahan isteri dalam keadaan kurang atau tidak ada nafkah itu bukan termasuk cara yang $m a^{c} r \hat{f} f$. Oleh itu isteri boleh memilih antara bersabar

\footnotetext{
${ }^{32}$ Daud, F. K., Tafsir Ayat-Ayat Hukum Keluarga
} 1, (Banten: Desanta Muliavisitama, 2020), 104 
atau menuntut perpisahan dengan suaminya (khuluc atau fasakh). Pendapat kedua ini lebih kuat.

Adapun masalah nafkah batin, apabila istri menolak untuk tidak melakukan hubungan suami istri, karena ada alasan yang dapat diterima. Misalnya suami mempunyai penyakit yang menular. Maka ini tidak dipandang sebagai nusyuz. ${ }^{33}$

\section{Hak Bekerja Istri}

Iran memberikan hak bekerja bagi istri. Namun, ada ketentuan yang membo-lehkan suami melarang istrinya bekerja pada suatu profesi yang tidak diinginkan-nya. Karena profesi tersebut dipandang tidak sesuai dengan visi keluarga atau dengan martabat dirinya sendiri sebagai perempuan atau isteri. ${ }^{34}$

Sebenarnya hukum perempuan bekerja tiada larangan dalam agama Islam. Akan tetapi mencari nafkah bukanlah tanggung-jawab istri. Hanya saja apabila nafkah suami tidak dapat mencukupi kebutuhan keluarga, maka istri boleh memberikan hasil keringatnya dengan kerelaannya untuk kepentingan keluarga. Bagi perem-puan yang demikian ada catatan kebaikan sendiri di sisi Allah swt.

\section{Perceraian}

Hukum Family Protection Act Iran telah meniadakan hak suami menyatakan talak secara sepihak. Pernyataan pasal 8, bahwa setiap perceraian, harus ada permohonan pada pengadilan terlebih dahulu, agar pengadilan mengeluarkan sertifikat 'tidak dapat berdamai

33 Aulia Rahmat, Perlindungan Hak-Hak Perempuan dalam Hukum Keluarga di Republik Islam Iran, Al-Muqaranah: vol. 4, no. 2, 2013, 40https:// pmhiainimambonjol.files.wordpress.com/2015/04/iv-22013-2-aulia-rahmat.pdf.

34 Aulia Rahmat, Perlindungan Hak-Hak Perempuan dalam Hukum Keluarga di Republik Islam Iran , ...., 38 https://pmhiainimambonjol.files.wordpress. com/2015/04/iv-2-2013-2-aulia-rahmat.pdf kembali.' Pengadilan akan mengeluarkan sertifikat tersebut setelah berupaya secara maksimal, tetapi tidak berhasil mendamaikan kedua-nya. Menurut Amandemen 1992, talak yang tanpa sertifikat (bukti talak) dari pengadilan tidak sah.

Pengadilan dapat mengeluarkan sertifikat 'tak dapat berdamai kembali' (keputusan fasakh) atas alasan-alasan berikut:

a. Salah seorang pasangan menderita gila yang permanen atau berulang-ulang.

b. Suami menderita impoten, dikebiri, atau alat vitalnya diamputasi.

c. Isteri mandul, menderita cacat seksual, lepra atau buta.

d. Suami atau isteri dipenjara selama 5 tahun.

e. Suami atau isteri mempunyai kebiasaaan yang membahayakan yang lain dalam kehidupan keluarga.

f. Seorang suami tanpa persetujuan isteri pertama, berpoligini.

g. Salah satu pihak mengkhianati pihak lain.

h. Kesepakatan suami isteri untuk bercerai.

i. Adanya perjanjian dalam akad nikah yang memberikan kewenangan pada pihak istri untuk menceraikan diri dalam keadaan tertentu.

j. Suami atau isteri dihukum, karena melakukan perbuatan yang dapat dipandang mencoreng kehormatan bangsa.

Undang-undang yang baru di Iran mengacu kepada hukum Islam. Maka, sesuai ketentuan fiqh, tidak memberikan aturan bahwa perceraian harus didahului permohonan ke pengadilan. Dalam fiqh telah memberikan hak cerai kepada suami dan istri, melalui talak dan khulu'.

8. Penyelesaian Perselisihan Melalui Arbitrator

Jika pasangan suami istri meminta bantuan dalam penyelesaian perselisihan mereka, maka Pengadilan dapat menye-rahkan 
penyelesaiannya pada arbitrator (hakam). Pengadilan akan menangani sendiri kasus yang berkaitan dengan validitas perjanjian pernikahan dan perceraian yang rumit kasusnya, dan tidak perlu diserahkan pada Juru Damai.

Juru Damai juga harus berusaha mendamaikan kembali pasangan suami istri yang bersengketa dalam jangka waktu yang telah ditentukan oleh pengadilan. Hasil dari kasus tersebut akan diserahkan pada pengadilan untuk ditindaklanjuti. Apabila Juru Damai (hakam) tidak ber-hasil mendamaikan atau menangani kasus tersebut dalam jangka waktu yang ditetap-kan, pengadilan akan mengambil alih serta memutuskan ketentuan selanjutnya. Hal ini demi ketertiban administrasi dan kelancaran dalam penetapan keputusannya.

\section{Hukum Waris}

Hukum waris diatur dalam pasal 86-93 Undang-Undang No. 188 Tahun 1959 dan lebih mencerminkan unifikasi syariat Islam mazhab Ja'fari. Adapun rukun-rukun waris dalam pasal 86 ayat (1): $:^{35}$ (1) Orang yang meninggal dan mewariskan disebut Murits; (2) Ahli waris, orang yang berhak dan masih hidup ketika Murits mati; (3) Ada harta yang ditinggalkan oleh Murits.

Dalam Hukum Kewarisan lama Iran (The Civil Code, 1959: 67-68), istri yang mempunyai anak dapat bagian 1/8 warisan suaminya tanpa harta berupa tanah. Jika suami-istri tersebut tidak ada anak, maka bagian istri $1 / 2$ dari tirkah. Pembagian sisanya melihat kondisi ahli waris yang ada, apabila ada ahli waris lain dari pihak almarhum suami, maka mereka mendapat sisanya. Tetapi jika tiada ahli waris lain, 1/2 harta tersebut diserahkan pada negara. Sebaliknya, apabila isteri yang meninggal dan pasangan itu tidak memiliki anak, suami

${ }^{35}$ Lihat Ayat [1] Pasal 86 Undang-Undang No. 188 Tahun 1959 Tentang Personal Status Law and Amendments. mendapatkan seluruh harta almarhumah isteri. Jika mempunyai anak, suami hanya mendapat $1 / 4$ (pasal 91). ${ }^{36}$

Sedangkan dalam Hukum Kewarisan baru, hak waris suami dan istri setara, tidak lagi mengenal perbedaan jenis kelamin. ${ }^{37}$ Dalam The Civil Code tahun 2000 pasal 67-68, seorang istri akan mendapatkan seluruh warisan suaminya. Jadi, dalam Hukum Kewarisan baru, isteri berhak mendapat tanah suaminya, yang sebelumnya tidak mendapatkannya dalam Hukum Kewarisan lama. ${ }^{38}$ Ini merupakan ketentuan hukum progresif sebagai upaya menyetaraan bagian antara hak laki-laki dan perempuan.

Pasal 88 Hukum Kewarisan lama mengatur penerima warisan, yaitu: (1) ke-rabat dekat atau ada hubungan perkawinan yang sah; (2) ada hubungan nasab; (3) penerima wasiat dari si mati; (4) bait al-mal (UU No. 188 Tahun 1959).

Pasal 89 berisi tentang beberapa ahli waris yang berhak mewarisi. Mereka ini yang dipandang kerabat dekat, sebagai-mana dalam ketentuan fiqh. Pasal 90 berisi tentang penegasan peraturan yang berlaku kewajiban dan hak yang berkaitan dengan waris (Pasal 90 UU No. 188 1959). ${ }^{39}$

\section{Wasiat Wajibah}

Pada pasal 74 Undang-Undang Iran No. 188 tahun 1959 mengatur wasiat wajibah, berbunyi:

36 Muhammad Fauzinuddin, Kontribusi Iran terhadap Sejarah Pembaharuan Hukum Keluarga Islam (Potret Sistem Kewarisan dan Wasiat Wajibah di Iran), ... 210 https://doi.org/10.18860/ua.v18i2.4492

${ }^{37}$ Pakzad, Sima. 1994. The Legal Status of Women in the Family in Iran, in M. Afkhami and E. Friedl (eds), In the Eye of the Storm Women in Postrevolutionary Iran. London: Taurus, 77-79

38 Schirazi, Asghar. 1997. The Constitution of Iran: Politics and The State in The Islamic Republic, translation from the German by John O'Kane. London: Tauris, 10-11

39 Muhammad Fauzinuddin, Kontribusi Iran terhadap Sejarah Pembaharuan Hukum Keluarga Islam, ......, 210 https://doi.org/10.18860/ua.v18i2.4492 
a. Jika anak meninggal (lelaki maupun perempuan), sebelum orang tuanya meninggal, maka ia diqiyaskan kepada hukum dimana ayah/ibunya meninggal dan hak waris pindah kepada anak-anaknya, sesuai hukum syariat yang berlaku dengan tidak lebih dari sepertiga harta tirkah.

b. Mengutamakan kewajiban wasiat daripada wasiat-wasiat yang lain dan tidak melebihi 1/3 dari harta warisan (pasal 74). Regulasi ba-tasan wasiat juga diatur dalam pasal 70 , bahwa tidak boleh sese-orang mewasiatkan lebih dari 1/3 tanpa mendapatkan izin dari Negara (pasal 70). Pewasiat seharusnya menunjuk suatu badan hukum (notaris) untuk mencatatkan wasiat terse-but, untuk dieksekusi setelah si pewasiat meninggal (pasal 75).

Oleh karena itu, si pewasiat wajib mencatatkan seberapa banyak hartanya yang hendak diwasiatkan, dalam bentuk apa dan kepada siapa diwasiatkan, sehingga semuanya dapat dicatat secara lengkap, jelas dan sah di suatu badan hukum (notaris).

\section{Harta Gono-Gini}

Ketentuan mengenai Harta Bersama (Suami-Istri) termaktub dalam pasal 940-948. ${ }^{40}$ Bahwa menikah secara temporal (mut'ah) maupun menikah secara perma-nen (daim), tetap dapat saling mewarisi (Pasal 940). Bagian warisan dari suami dan isteri telah diatur (Pasal 941). Bagi yang berpoligini, bagian $1 / 4$ atau $1 / 8$, dibagi sama rata di antara para istri (Pasal 942). Jika suami telah mentalak isterinya, tetapi perceraian telah dibatalkan, salah satu dari mereka meninggal dunia sebelum berakhirnya periode 'iddah, mereka dapat saling mewarisi. Tetapi jika kematian salah satu dari mereka terjadi setelah berakhirnya 'iddah, atau jika

40 Muhammad Fauzinuddin, Kontribusi Iran terhadap Sejarah Pembaharuan Hukum Keluarga Islam ....., 214 https://doi.org/10.18860/ua.v18i2.4492 perceraian itu tidak dapat dibatalkan, mereka tidak dapat saling mewarisi (Pasal 943). Jika suami mentalak istrinya ketika ia sakit, dan mati itu penyakit yang sama dalam waktu satu tahun dari perceraian, istri berhak atas warisannya, bahkan jika perceraian yang tidak dapat dibatalkan; asalkan istri belum menikah lagi (Pasal 944). Apabila seorang lelaki menikahi seorang perempuan ketika ia sakit lalu wafat karena penyakit yang sebelum penyempurnaan pernikahan, istri tidak dapat warisan darinya; tetapi bila ia meninggal setelah penyempurnaan, atau setelah sembuh dari penyakit itu, isteri mendapat warisan darinya (Pasal 945). Suami mendapat warisan dari seluruh harta isteri; tapi isteri hanya membutuhkan waktu dari harta bergerak dan dari bangunan serta tanamtanaman (Pasal 946). Istri mengambil warisan dari harta bangunan dan tanam-tanaman yang dinilai tetap di tanah, namun tanpa membayar tenaga kerja (Pasal 947). Jika, dalam Pasal sebelumnya, ahli waris menolak untuk membayar harga bangunan dan tanaman, perempuan mungkin menyadari dirinya tepat di hal tersebut dari hal itu sendiri (Pasal 948).

\section{Pernikahan Mut ${ }^{\mathrm{c}}$ ah (Sîgheh)}

Nikah mut'ah atau munqati' oleh kalangan masyarakat Iran disebut 'sîgheh', di sini penting untuk difahami perkem-bangan dan realitas hukum keluarga di Iran, karena Iran merupakan Negara yang menganut Syiah. Dalam buku putih Syiah dinyatakan, bahwa sebagian ulama Syiah seperti Ibnu al-Babawiyah dan al-Kasyany menyatakan bahwa nikah Mut'ah itu agama kami dan agama moyang kami. Barang siapa mengamalkannya berarti telah mengamalkan agama dan barang sia-pa telah mengingkarinya berarti telah me-langgar agama, maka dia tidak termasuk dari agama kami. Mereka juga berkeya-kinan bahwa barangsiapa yang pernah melakukan kawin mut'ah sekali, maka derajatnya sama dengan Al-Husain bin Ali (cucunda Nabi Muhammad 
saw). Barang siapa pernah melakukannya dua kali, maka derajatnya sama dengan Ali bin Abi Thalib, dan barang siapa pernah melaku-kannya empat kali, maka derajatnya akan sama dengan Rasulullah saw. ${ }^{41}$ Para penganut Syiah sangat meyakini ajaran tentang seruan nikah mut'ah.

Nikah Sigheh secara resmi tercantum dalam Qanun Madani Iran, dan dinyatakan dalam Hukum Keluarga (Droit civil la famille) huqûqe khânevâdeh). Dalam Undang-Undang tersebut dinyatakan bahwa ada dua jenis perkawinan yang dianggap sah menurut hukum positif Iran; nikah permanen (dâim) dan nikah temporal (munqati'). Nikah jenis kedua ini disebut nikah sîgheh atau muaqqat di Iran.

Namun, nikah sîgheh ini di era modern secara de facto sebenarnya jarang diprak-tikkan oleh masyarakat Iran, bahkan pelan-pelan seakan semakin ditinggalkan oleh masyarakat lokal. Tetapi terkadang dekat Haram Sayyidah Fatimah Ma'someh terdapat perempuanperempuan yang mau dimut'ah. Ciri-ciri mereka dengan mema-kai chador terbalik, tetapi orang akan kesulitan membedahkan mana chador terbalik atau tidak. ${ }^{42}$

Bagaimanapun keyakinan mereka masih kuat bahwa nikah mut'ah tidak diharamkan dalam agama dan memiliki banyak kebaikan. Misalnya daripada kumpul kebo tanpa menikah. Oleh karenanya, secara de-jure memang ada aturannya. Keyakinan ini dibangun oleh para ulama pendahulu mereka dengan merujuk kepada al-Qur'an dan pada beberapa riwayat yang diklaim dari para Imam mereka, juga dari hasil ijtihad ulama' (Syiah). Sumber

41 Daud, F. K., Nikah Kontrak Modus Human Trafficking (Kritik atas Fiqh Munakahah Syiah), Jurnal Al Hikmah: (K. Daud, 2018, p. 256), 252-270 http://doi. org/1036835/hjsk.v8i2.3388

42 Sukron Makmun, Fenomena Pernikahan Mut'ah di Republik Islam Iran (Antara Ada dan Tiada), Jurnal MUWAZAH, vol. 1, no. 2, 2009, 153<http://ejournal.iainpekalongan.ac.id/index.php/Muwazah/ article/view/290> hukum nikah mut'ah tersebut, menurut fuqahâ' Imâmiyah terdapat pada surat al-Nisa': 24:

Artinya: Dan (diharamkan juga kamu mengawini) wanita yang bersuami, kecuali budak-budak yang kamu miliki (Allah telah menetapkan hukum itu) sebagai kete-tapan-Nya atas kamu. Dan dihalalkan bagi kamu selain yang demikian (yaitu) men-cari isteri-isteri dengan hartamu untuk di-kawini bukan untuk berzina. Maka isteri-isteri yang telah kamu nikmati (campuri) di antara mereka, berikanlah kepada mere-ka maharnya (dengan sempurna), sebagai suatu kewajiban; dan tiadalah mengapa bagi kamu terhadap sesuatu yang kamu telah saling merelakannya, sesudah me-nentukan mahar itu. Sesungguhnya Allah Maha Mengetahui lagi Maha Bijaksana.

\section{Analisis Perkembangan Hukum Keluarga Islam Di Iran}

Hukum Keluarga Islam di Republik Iran telah mengalami perubahan yang signifikan mulai tahun 1906 atau tepatnya 1927 hingga 1979. Apabila dianalisa, perkembangan ini tidak berbeda dengan Negara-negara Islam lainnya, seperti di Mesir, Maroko maupun di Indonesia, dimana tidak dapat dilepaskan dari proses modernisasi karena proses itu melahirkan suatu situasi dan pengalaman yang berbeda. Di sinilah proses pembaharuan itu terjadi dengan alasan bahwa masyarakat menginginkan perubahan. ${ }^{43}$ Sedangkan dari segi pemerintahan, salah satu alasan utamanya adalah efisiensi birokrasi hukum dalam Reformasi hukum keluarga dan tata negara bangsa, serta modernisasi undangundang lokal disesuaikan dengan kepentingan humanisme tingkat global. Tuntutan ini telah mendorong negara-negara Muslim untuk memodifikasi hukum materiil dan melengkapi

43 Anderson, J.N.D., "Modern Trends in Islam: Legal Reform and Modernization in the Middle East", The International and Comparative Law Quarterly, Vol. 20. No. 1 (Januari, 1971): 355 
prosedur administrasi peradilan negara modern dengan melahirkan hukum acara Islam. ${ }^{44}$

Proses pembaharuan yang liberal di Iran ini tak lepas dari kepemimpinan Iran terutama sejak 1927 hingga 1979, yang menginginkan Iran maju dan modern seperti Barat. Selain penggubalan Undang-Undang Islam, termasuk juga hukum keluarga dikodifikasi kemudian berubah menjadi Protection of Family tahun 1975.

Selain itu, mulai tahun 1925-1979, ada larangan pemakaian jilbab dan yang berjilbab disanksi. Jadi era itu perempuan Iran diberi kebebasan, dengan gaya busana layaknya bintang Hollywood. Perempuan Iran tak ragu berbusana kasual, dan rambut yang ditata dengan ber-make up wajah. Larangan jilbab ini sempat mendapat kecaman dari ulama, tetapi ulama yang dipandang melawan rezim akhirnya disingkirkan. Di sisi lain, lahir sejumlah kaum Muslim intelektual, bahkan antaranya dari para ulama di Iran yang sudah mulai membaca ulang mașadir al-Islâm. Antaranya ada Ayatullah Murtada Mutahhari (Khurasan, 1919-1979), seorang Ulama yang alim, murid 'Allamah Țaba'țabaī, yang juga ikut konsen dalam perjuangan isu gender di Iran. ${ }^{45}$ Tetapi beliau kemudian terkena serangan bom tahun 1979. Belakangan muncul nama Ziba Meer Husseini, juga seorang intelektual, antropolog dan penulis yang juga merupakan intelektual Muslimah asal Iran yang konsen kepada isu gender. Para intelektual di sana ini sudah mulai banyak yang konsen pada isu gender, dengan mengkritisi beberapa kitab ulama klasik dan risalah-risalah fuqaha abad pertengahan yang

44 Anderson, J.N.D., "Modern Trends in Islam: Legal Reform and Modernization in the Middle East", The International and Comparative Law Quarterly, ....., 10-33

45 Mutahhari, Murtada. 1981. The Rights of Women in Islam, translation of Nizam-e huquq-e zan Dar Islam, 1353 (1974). Tehran: WOFIS dipandang bias gender. Selanjutnya kemudian terjadi proses tadwin (kodifikasi) dan tawdi' (legislasi). Menurut Tahir Mahmood, pada tataran metodologis, pembaharuan hukum Islam bersandarkan kepada doktrin masawat alMadzahib fi al-fiqh (persamaan mazhab hukum Islam), istihsan, masalih al mursalah, istidlal, tadwin dan tawdi'. ${ }^{46}$

Namun, pemerintahan yang baru telah menghapuskan jejak Syah Reza Pahlavi untuk menempatkan pengadilan yang sekuler atas permasalahan keluarga. Sepertinya kaum revolusioner Iran yang baru tidak terlalu peduli pada hak-hak perempuan. Kaum revolusioner bukan tidak saja ingin membe-baskan Iran dari pengaruh politik dan ekonomi Amerika Serikat, tetapi juga ingin menghi-langkan pengaruh pemimpin sebelumnya.

Cadar diberlakukan kembali, yang menjadi ciri khas perlawanan terhadap Barat dan sekaligus anti-Syah Iran. ${ }^{47}$ Slogan yang beredar pada tahun 1979, “Kematian bagi mereka yang menanggalkan jilbab.” Pada 1983 diputuskan hukuman bagi mereka yang tidak menutup rambutnya dengan 74 cambukan. Sejak 1995, ada peraturan bagi perempuan yang tidak menutup kepala (jilbab) dikurung selama 60 hari.

Keadaan ini rupanya tidak mudah bagi masyarakat Iran untuk menerimanya. Sebagai responsnya, sebagian masyarakat melakukan demo turun ke jalan, bahkan berkali-kali untuk memprotesnya. Namun hal itu kelihatannya hanya memberi impak kecil saja, sehingga cara berbusana perempuan Iran tidak berubah drastis. Fenomena tersebut dapat disaksikan pada saat ini, Iran tetap tidak seketat di Saudi. Betapa pun regulasi diterapkan, realitanya tidak semua perempuan Iran memilih bercadar hitam

46 Mahmood,Tahir, Personal Law in Islamic Countries,....., 13

47 Elvi Soeradji, Dinamika Hukum Islam di Iran,. , 49 http://digilib.iainpalangkaraya.ac.id/id/eprint/2392 
atau memakai chador, di antara mereka masih ada yang memilih berkerudung longgar dengan mantel.

Sejak Revolusi Iran, tercatat dalam mukaddimah Konstitusi Republik Islam Iran, mengakui persamaan derajat antara lakilaki dan perempuan di depan hukum. Namun gerak perempuan di publik dibatasi. Meskipun sudah berkali-kali para perempuan ini berdemo turun ke jalanan ibukota Teheran dengan tanpa jilbab. Aksi tersebut setidaknya menunjukkan satu hal, yakni respon keengganan perempuan Iran yang diatur wilayah privatnya, agar ada kebebasan berekspresi bagi mereka. Akibat aturan baru tersebut, tak sedikit warga Iran yang meninggalkan negaranya. Bahkan di era Hassan Rouhani, perempuan Iran memakai kerudung dengan di bagaian depannya masih terlihat rambutnya.

Pada 1982 Majelis Hakim Agung mengumumkan kepada tiap Pengadilan agar hukum perkawinan yang ada disesuaikan dengan hukum Islam (Syiah). Syariah yang dianut di Iran saat itu sangat 'patriarchal'. Sehingga hukum perkawinan Iran secara tradisional kembali menguntungkan para suami. Hak cerai ada pada suami. Apabila seorang istri ingin bercerai, maka ia harus mempunyai beberapa alasan yang legal. Misalnya, suaminya telah melakukan kekerasan, memiliki masalah psikologis atau tidak sanggup menafkahi. Praktik poligini dan nikah mut'ah bebas. Meskipun demikian, poligini kini ditentang, bukan saja dari kalangan aktivis perempuan, tetapi juga dari sebagian besar masyarakat Iran. Promosi praktik poligini pada tahun 2019, justru dipandang sebagai iklan pelacuran secara legal. ${ }^{48}$

Demikian juga tentang nikah mut'ah, masyarakat Iran sudah banyak yang menya-

48 Promosi Praktik Poligami oleh Kaum Konservatif, https:/news.detik.com/dw/d-4782791/ promosi-praktik-poligami-oleh-kaum-konservatif-picukontroversi-di-Iran. diakses pada 28 Mei 2021 dari dampak buruk dari pernikahan mut'ah ini, sehingga lambat laun mulai ditinggalkan. Selain itu, karena dalam urusan warisan akan mengacaukan, anak hasil pernikahan mut'ah mendapat jatah waris dari ayah biologisnya, sebagaimana disebutkan dalam qawâide âmereh dan nuzhûme umûmy. Selain itu, ter-dapat anak-anak yang terbiar tanpa penjagaan hasil dari pernikahan mut'ah, sehingga di Yayasan Yatim Piatu dipenuhi dengan anak-anak yang lahir tidak mempunyai ayah yang jelas. Sejak 1995-1998 banyak hal yang terjadi, Iran kini dipandang sebagai Negara yang moderat.

Namun, sejak 2006, tingkat perceraian melambung tinggi di Iran, yang belum pernah terjadi sebelumnya. Bahkan ironisnya, perceraian tersebut dirayakan dengan pesta suka ria lengkap dengan undangan yang sarkastik. Fenomena tersebut sempat menghangat di Teheran dan beberapa kota lainnya. Menunjukkan bahwa para perempuan itu bahagia bisa lepas dari suaminya. ${ }^{49}$

Menurut penulis, hal itu bisa terjadi akibat dari adanya pergeseran undang-undang keluarga yang sebelumnya telah memberikan kebebasan perempuan yang luas, juga adanya perubahan di tingkat internal masyarakat. Misalnya, meningkatnya pendidikan perem-puan dengan pengalaman dan skill yang mereka miliki menjadikan para perempuan tidak ingin lagi didominasi laki-laki. Terlebih hal itu dikuatkan oleh UU keluarga Iran pasca-Revolusi yang seakan kurang pro-perempuan.

\section{PENUTUP}

Menarik diperhatikan, meskipun Republik Islam Iran mayoritas penganut mazhab Ja'fari, tetapi dalam perjalanan legislasinya, hukumhukumnya dari awal hingga era kini, merupakan

49 Tren Baru: Pesta Perceraian di Iran, https://www.cnnindonesia.com/gaya-hidup/20141027080500-284-8229/tren-baru-pesta-perceraian-di-iran. diakses pada 29 Mei 2021 
hasil kompromi antara mazhab Imamiyah Syi'ah dan Sunni Hanafi. Sebelum lahirnya marriage law di Iran, masalah perceraian dan pernikahan ditetapkan dalam Qonun Madani yang berlaku sejak 1930. Kemudian marriage law digantikan family Protection Act tahun 1967, lalu ditukar dengan Protection of Family tahun 1975. Namun post-revolusi Iran (1979), Protection of Family ini dihapuskan, yang dipandang telah melampaui ketetapan syariah Islam. Adapun hukum yang belum dikodifikasi harus dikembalikan kepada fiqh Istna Asy'ariyah. Hal ini menunjukkan bahwa hukum keluarga telah terjadi adanya tarik menarik antara ulama dan elit sekuler. Namun terdapat fenomena baru, tingkat perceraian di Iran justru meningkat dratis, poligini dan nikah mut'ah mulai ditinggalkan, bahkan ditolak. Fenomena ini antaranya dipengaruhi oleh faktor modernisasi di era Pahlevi. Dimana dampaknya, banyak perempuan yang berpendidikan tinggi dan akhirnya memahami akan hak-haknya sebagai perempuan. Termasuk ada pengaruh dari isu global terkait wawasan isu gender. Sehingga praktik poligini dan nikah mut'ah justru dipandang membawa madarat bagi perempuan dan keluarga..

\section{DAFTAR PUSTAKA}

Abdullahi A. an-Na'im, Islamic Family Law in a Changing World: A Global Resource Book (London: Zed Book Ltd.). 2003

Akhavi. "Iran, The Oxford Encyclopedia of The Modern Islamic World." edited by John L. Esposito, 225. Oxford: Oxford University Press, 1995.

Arifin, Tajul \& Bisri, Cik Hasan. Muslim Family Law in Asian and African Countries. Bandung: Research Center IAIN.2002.

Aulia Rahmat, Perlindungan Hak-Hak Perempuan dalam Hukum Keluarga di
Republik Islam Iran, Al-Muqaranah: vol. 4,no. 2.2013.https://pmhiainimambonjol. files.wordpress.com/2015/04/iv-2-20132-aulia-rahmat.pdf

Don Peretz, The Middle East Today (New York: Preegar, 1986)

Hoodfar,Homa,FamilyLawandFamilyPlanning Policy in Pre- and Post-Revolutionary Iran, (London: Routledge, 2008) https// doi.org/10.4324/9780203894057

Homaidi Hamid, Hukum Keluarga Iranl, Hukum Keluarga di Dunia Islam Modern, ed. M. Atho' Muzdhar, dkk. (Ciputat: Ciputat Press, 2003).

Hukum Perkawinan, 1931, pasal 1

Iran News, Payvand.com. Irans Population growth rate falls to 1,5 percent: UNFP, Diakses pada tanggal 27 Mei 2021.http:// www.payvand.com/news/04/aug/1017. html.

Kedutaan Republik Indonesia Iran, 2008, Selayang Pandang Republik Islam Iran, (Tehran: KBRI).

Daud, Fathonah K., 2018, Nikah Kontrak Modus Human Trafficking (Kritik atas Fiqh Munakahah Syiah), Jurnal Al Hikmah: vol. 8, no. 2, 2018, 25 2-270 http://doi. org/1036835/hjsk.v8i2.3388.

Daud, Fathonah K., Tafsir Ayat-Ayat Hukum Keluarga 1, Banten: Desanta Muliavisitama, 2020

L. Esposito, Jhon, Ensiklopedi Oxford Dunia Islam Modern, Jil. 2, Penerj. Eva Y.N. dkk, Bandung: Mizan, 2001.

Mallet, Chibli, Jane Connors (eds.), 'Islamic Family Law (Arab and Islamic Laws Series)'- Graham \& Trotman, 1990.

Mallet, Chibli.The Renewal of Islamic Law: Muhammad Baqer as-Sadr, Najafand the Shi'i International. Cambridge: Cambridge University Press.1993

Mir Hossein, Ziba, Marriage on Trial: a Study 
of Islamic Family Law, Iran and Marocco Compared, (London: St. Martin's Press, 1993).

Moojan, Momen. An Introduction to Shi'i Islam. New Heaven: Yale University Press.1985

Mughiyah,Muh. Jawad,Fiqh Perbandingan Lima Mazhab,ed.Masykur A.B. Jakarta: Lentera,1999.

Muhammad Fauzinuddin,Kontribusi Iran terhadap Sejarah Pembaharuan Hukum Keluarga Islam (Potret Sistem Kewarisan dan Wasiat Wajibah di Iran), Ulul Albab, vol. 18, no. 2 (2017) https://doi. org/10.18860/ua.v18i2.4492

Mutahhari, Murtada. 1981. The Rights of Women in Islam, translation of Nizamehuquq-e zan Dar Islam, 1353 (1974). Tehran: WOFIS.

Pakzad, Sima. The Legal Status of Women in the Family in Iran, inM. Afkhami and E. Friedl (eds), In the Eye of the Storm Women in Postrevolutionary Iran. London: Taurus. 1994

Promosi Praktik Poligami oleh Kaum Konservatif,https://news.detik.com/dw/ d-4782791/promosi-praktik-poligamioleh-kaum-konservatif-picu-kontroversidi-Iran. diakses pada 28 Mei 2021.

Sachiko, Murata. Temporary Marriage in Islamic Law. Electronic publication based on MA dissertation completed in 1974 at the Faculty of Theologyat Tehran University (most of the Persian text has been published underthe title izdiwaz- $i$ muwaqqat: mut'a sigha. Tehran: Hamdani, 1358/1979)www.Al-Islam.org/ organizations/dilp, the Ahlul BaytDigital Islamic Library Project.
Schirazi, Asghar. The Constitution of Iran: Politics and The State in The Islamic Republic, translation from the German by John O'Kane. London: Tauris, 1997

Soeradji, Elvi, Dinamika Hukum Islam di Iran, Jurnal HIMMAH, Vo. 8 (22), Mei 2007, 38 http://digilib.iain-palangkaraya.ac.id/ $\mathrm{id} /$ eprint/2392.

Stewart, Devin J. Islamic Legal Orthodoxy: Twelver Shiite Responses to The Sunni Legal System. Salt Lake City, UT: University of Utah Press, 1998.

Sukron Makmun, Fenomena Pernikahan Mut'ah di Republik Islam Iran (Antara Ada dan Tiada), Jurnal MUWAZAH, vol. 1, no. 2 (2009). <http://e-journal. iainpekalongan.ac.id/index.php/ Muwazah/article/view/290>.

Suma, Muhammad Amin, Hukum Keluarga Islam di Dunia Islam, Jakarta: Rajawali Grafindo, 2005

Syarifuddin, Amir, Hukum Perkawinan Islam di Indonesia, Jakarta: Kencana, 2007.

Mahmood,Tahir, Family Law Reform in the Muslim World (New Delhi; The Indian law Institute, 1972

Mahmood,Tahir, Personal Law in Islamic Countries, New Delhi, 1987.

Tim Ahlul Bait Indonesia, Buku Putih Mazhab Syiah,Jakarta: Dewan PP ABI, 2012.

Toha Andiko, Pembaharuan Hukum Keluarga di Dunia Islam (Analisis terhadap Regulasi Poligami dan Keberanjakannya dari Fiqh), NUANSA: vol. 12, no. 2 (2019) http://dx.doi.org/10.29300/ nuansa.v12i2.2807 